FELIPE CORVALÁN T. Editor revista de arquitectura

\section{Espacio público y ciudadanías}

as recurrentes manifestaciones que han tenido lugar en el último tiempo, de manera sostenida y

Len diversas partes del mundo, no sólo son la expresión de anhelos y reivindicaciones que aspiran modificar de manera profunda el modelo político y económico que rige las acciones de la sociedad contemporánea. También, estas movilizaciones pueden ser entendidas como la confirmación y evidencia de la importancia del espacio público como ámbito primordial de la interacción social, espacio de visibilidad en el cual las demandas ciudadanas, las diferencias y el conflicto se hacen presentes intentando encontrar su lugar de expresión, combatiendo el statu quo que mantienen el orden y sentido de las cosas previamente establecido.

Un espacio público que paradóiicamente y pese a esta reciente activación, se vuelve cada vez más difuso y complejo, tanto en términos físicos como discursivos. Esto en la medida en que el ámbito y lugar de lo público se ve amenazado por el ímpetu de los procesos de privatización, las estrategias de control que intentan medir usos y comportamientos y la segregación social que jerarquiza y limita el acceso a las oportunidades que éste puede ofrecer. ¿̇Es realmente el espacio público contemporáneo el lugar de lo colectivo? ¿̇Propician nuestras ciudades la interacción y encuentro entre sus ciudadanos? ¿̇Podemos entender al espacio público como la expresión de ciudadanías diversas o solamente como un campo homogéneo y normado?

En este escenario, el presente número de revista de arquitectura propone volver a pensar las posibilidades ofrecidas por el espacio público, ya sea a partir de su capacidad de hacer converger los asuntos de interés colectivo, o bien expresando la diversidad que compone al tejido social. Una diversidad que nos recuerda que al interior de lo que llamamos ciudadanía subyace un conjunto de particularidades distintivas, muchas veces encontradas entre sí, que enriquecen el debate al interior del espacio público y el potencial significativo de éste, que además requiere ser pensado a partir de las potencialidades que hoy configuran el debate en torno a la ciudad, incorporando conceptos tales como movilidad, sostenibilidad o la rehabilitación de espacios en desuso.

Bajo estos parámetros podemos entender la relación entre el espacio público y la ciudadanía como un escenario en permanente tensión, entendiendo la disciplina arquitectónica y la planificación urbana como el encuentro entre concepto y experiencia, entre aquellas estrategias que conceptualizan y definen los límites y la contingencia que permite activar y resignificar los valores del espacio en cuestión. Es precisamente este doble acceso el que intentamos proponer a través de los artículos que se despliegan a continuación, el diálogo entre teoría y práctica, entre la conceptualización del espacio público y aquellas modificaciones empíricas que permiten la apropiación de los ciudadanos. 